23. -27.9 .1982$

18. -21.11 .1982$
VII. Commonwealth and International Conference on Sport, Physical Education and Dance. Brisbane, Australia.

Kontakt: Dr. Allan Y. Coles, Dept. of Human Movement Studies, University of Queensland, St. Lucia, Qld., 4067 Australia.

International Symposium on Research in School Physical Education. Jyväskylä, Finland.

Kontakt: Prof. Risto Telama, University of Jyväskylä, 40100 Jyväskylä 10. Finland.

\title{
Internationaler Preis für Sportsoziologie
}

Das Internationale Komitee für Sportsoziologie (ICSS) des Weltrats für Sport und Leibeserziehung (ICSPE) und der Internationalen Gesellschaft für Soziologie (ISA) hat für das Jahr 1982 einen Preis für junge Wissenschaftler (Junior Scholar Award) ausgelobt, der für eine grundlegende sportsoziologische Arbeit theoretischer und/oder empirischer Art vergeben wird. Die Auszeichnung soll beim Weltkongreß für Soziologie vom 16. bis 21. 8.1982 in Mexico City verliehen werden. Sie ist mit 300 US-Dollar dotiert. Der Empfänger erhält außerdem für die Reise nach Mexico einen Zuschuß in Höhe von 200 US-Dollar.

Bewerbungen sind bis zum 31. Januar 1982 an Professor Dr. Klaus Heinemann, Universität, Schneidershof, D-5500 Trier, zu richten. 